\title{
Defining Stress among Corrections Professionals
}

\section{Jessica Ballin'1, Meike Niederhausen², Kerry S. Kuehl'1, Diane L. Elliot ${ }^{1}$, Wendy McGinnis', Carol De Francesco ${ }^{1}$}

\author{
${ }^{1}$ Department of Health Promotion \& Sports Medicine, Oregon Health \& Science University, Portland, OR, USA \\ ${ }^{2}$ Oregon Health \& Science University-Portland State University School of Public Health, Oregon Health \& Science University, \\ Portland, OR, USA \\ Email: ballin@ohsu.edu, kuehlk@ohsu.edu
}

How to cite this paper: Ballin, J., Niederhausen, M., Kuehl, K.S., Elliot, D.L., McGinnis, W. and De Francesco, C. (2021) Defining Stress among Corrections Professionals. Open Journal of Preventive Medicine, 11, 237-250.

https://doi.org/10.4236/ojpm.2021.116019

Received: May 4, 2021

Accepted: June 8, 2021

Published: June 11, 2021

Copyright $\odot 2021$ by author(s) and Scientific Research Publishing Inc. This work is licensed under the Creative Commons Attribution International License (CC BY 4.0). http://creativecommons.org/licenses/by/4.0/

\section{Open Access}

\begin{abstract}
Corrections professionals experience high levels of acute and chronic work-related stress. This stress leads to increased mental and physical illness, early disability and mortality, and increased healthcare costs. Reducing stress requires identifying and prioritizing factors that contribute to it. Corrections professionals $(n=296)$ working at six different Oregon Department of Corrections facilities completed a cross-sectional survey, including demographics, work history and validated stress and occupational constructs. The outcome of perceived stress was measured using the Perceived Stress Scale (PSS-4 Short Form). Using a linear mixed effects regression model, we found that perceived stress increases with increased work-related stress $(p=0.02)$, work hours $(\mathrm{p}=0.03)$, operational stressors $(\mathrm{p}=0.002)$, and lack of procedural injustice $(\mathrm{p}=0.03)$ and decreases with more time employed at current facility $(\mathrm{p}=0.06)$, improved job satisfaction $(\mathrm{p}<0.001)$, and among married or partnered individuals $(\mathrm{p}=0.05)$. Identifying these predictors of stress can inform the development of policy changes to mitigate the stress of this challenged work force.
\end{abstract}

\section{Keywords}

Perceived Stress, Corrections Professionals, Work-Related Stress,

Occupational Stressors, Procedural Justice

\section{Introduction}

The World Health Organization has declared work-related stress as one of the greatest challenges of the twenty-first century [1]. Previous research has identi- 
fied high levels of chronic stress among corrections professionals [2] [3]. These high levels of chronic stress negatively impact mental well-being, physical health and job performance [4] [5]. Compared to other occupations, corrections professionals experience some of the highest rates of depression, suicide, obesity, sleep disorders, metabolic syndrome, and cardiovascular disease [6] [7] [8] [9] [10]. Further, this occupation is associated with high rates of injury, sick leave and healthcare costs [11].

Corrections professionals have a critical role in inmate rehabilitation, operating secure prisons and protecting our communities. Accordingly, maintaining the well-being of this largely unseen workforce is critical for public safety. Designing effective stress reduction interventions requires identifying and prioritizing the factors contributing to corrections professionals' stress.

Previous research from the U.S. Department of Justice has suggested that sources of stress for corrections professionals include hypervigilance, constant threats of violence, media scrutiny, a closed work environment, understaffing, and organizational issues as well as work and family conflicts [12]. On the other hand, some researchers have suggested other work-related factors' contribution to stress, such as dangers related to Adults in Custody (AIC's), long work hours, and lack of administrative support [13] [14]. No previous studies have concurrently indexed the effect of different work factors on corrections professionals' stress levels.

The main objective of this study was to define a comprehensive cross-sectional model for stress among corrections professionals by determining which occupational constructs, demographics, and work history variables contribute most to stress.

\section{Materials and Methods}

\subsection{Participants}

This study was a cross-sectional survey assessment of Oregon corrections professionals working directly with AIC's. Participants were recruited from six Oregon Department of Corrections facilities within 50 miles of Oregon Health \& Science University in Portland, Oregon. All corrections staff were eligible to participate if they worked directly with AIC's for at least one month. Participants responded to surveys which concurrently addressed various work and stress related questions regarding their overall opinions or experiences within the past month.

\subsection{Surveys}

Surveys included information on demographics, work history, perceived stress, and occupational constructs. Pen and paper self-report surveys were administered and collected on-site at each participating correctional facility during day, swing, and night shifts over several days. Researchers toured the facility and de- 
livered surveys directly at each post for those who were interested in participating. Site liaisons and staff coverage allowed staff to complete surveys during their work shift. Written informed consent was obtained prior to participation. These paper surveys were scanned and cleaned by researchers using Tele Form software system.

\subsubsection{Demographics and Work History}

Demographics collected included age (years), gender, race (Asian, Black/African American, Native American/Native Alaskan, Native Hawaiian/Other Pacific Islander, Hispanic/Latino, more than one race, and Non-Hispanic white), education (high school/General Educational Development GED/some college, two-year Associates degree, or four-year Bachelor's degree/more), current relationship status (married/partnered or not married/partnered), and military service (ever active duty in U.S. armed services or never served). Work history variables included time employed at current facility (years), security level of AIC's primarily worked with in the past month (minim, medium, or maximum security), post primarily worked in the past month (non-housing, general population, or special housing/segregation units), shift primarily worked in the past month (day, swing, night), and average hours worked per week in the past month.

\subsubsection{Perceived Stress}

The Perceived Stress Scale (PSS-4 Short Form) [15] was used to measure perceived stress among participants. For this construct, participants rated on a five-point Likert scale ( $1=$ None of the time, $5=$ All of the time) how often they felt in the past month about the following: that they were able to control important things in their life, confident about their ability to handle personal problems, that things were going their way, and that difficulties were piling up so high that you could not overcome them. A total stress score was created by adding the responses from the four questions together after reverse coding for the first three questions.

\subsubsection{Occupational Constructs}

Based on previous research, the following occupational constructs were examined as potential predictors of stress among corrections professionals: factors related specifically to the job itself, including work-related stress [16] [17] and work overload [18]; factors related to environment, such as environmental safety and dangerousness [16] [17] [18] [19], possibility of AIC conflict [20] [21], and experienced and witnessed violence [14]; organizational-specific conditions such as organizational and operational stressors [13] [22] [23], resource insufficiency [20] [21], procedural justice, and organizational support [16] [17] [24]; relationships at work, such as supervisor [17] [18], and coworker support [16]; other stressors outside of work, such as public image [18]; and contentment including job satisfaction [17] and intentions to quit [25]. 
Occupational constructs also include Likert scale responses. Resource insufficiency, possibility of AIC conflict, organizational stressors, operational stressors include ratings for how much of the following as contributed to stress experienced in the past month $(1=$ not at all, $5=$ very much $)$ in respect to corrections professionals' resources (management support, guidelines), AIC relations (possibility of violence and incidents), administration (staff shortages, leadership styles), and work life balance (shift work, over-time demands, social life limitations) respectively. Experienced and witnessed violence constructs included how often have threat, assaults without a weapon, and assaults with a weapon have occurred during the last six months $(0=$ rarely, less than once a month, $4=$ more than a week), which was later reclassified to rarely (less than once a month) and once a month or more due to limited distribution of responses.

The remaining constructs included ratings about overall agreement $(1=$ Strong disagree, 5 = strongly agree). Work-related stress rates negative feelings towards (fatigue, worry, anger), while work overload assesses difficulty and complexity of job demands. For the environmental safety and dangerousness constructs participants rate perceived risk among AICs. Supervisor, co-worker, and organizational support assesses negative feelings towards supervisors, co-workers, and the current institution's ability to assist with job demands. Procedural justice refers to inconsistent and unclear policies and organizational decision-making. Public image refers to participants' attitudes towards negative media coverage in the portrayal of corrections professionals' role. Job satisfaction includes questions related to positive attitudes towards current work (enjoyment, pride) and intentions to quit reflect attitudes towards leaving corrections work or current facility.

\subsection{Statistical Analyses}

Perceived stress was analyzed using a linear mixed effects regression model, with a random effect for the six different correctional facilities to account for the correlation among corrections professionals within each facility. A purposeful selection approach [26] was used to build the model considering the occupational constructs, demographics, and work history variables as possible predictors of perceived stress. Lastly, model diagnostics confirmed the final model by checking model assumptions. The statistical software $\mathrm{R}$ version 3.6.2 was used to conduct all statistical analyses.

\section{Results}

Participation varied across the six facilities and averaged 34\%, with a total of 330 surveys collected. Thirty-four participants were excluded from analysis due to missing information for perceived stress, occupational constructs, demographics, or work history $(n=296)$. However, no more than $1.5 \%$ were missing for any one variable.

Demographic, work history characteristics, and perceived stress among the final sample $(n=296)$ are described in Table 1 . Participants were mostly middle 
Table 1. Corrections professionals' demographics and work history $(\mathrm{n}=296)$.

\begin{tabular}{|c|c|}
\hline & n (\%) \\
\hline Age, years (Mean \pm SD) $[$ Min, Max] & $43.6 \pm 11.6[22,73]$ \\
\hline \multicolumn{2}{|l|}{ Gender } \\
\hline Female & $108(36.5 \%)$ \\
\hline Male & $188(63.5 \%)$ \\
\hline \multicolumn{2}{|l|}{ Race $^{\mathbf{a}}$} \\
\hline White (Non-Hispanic) & $278(84.2 \%)$ \\
\hline Hispanic/Latino & $35(10.6 \%)$ \\
\hline Native American/Native Alaskan & $19(5.8 \%)$ \\
\hline Black/African American & $10(3.0 \%)$ \\
\hline Asian & $9(2.7 \%)$ \\
\hline Native Hawaiian/Other Pacific Islander & $6(1.8 \%)$ \\
\hline Other & $5(1.5 \%)$ \\
\hline \multicolumn{2}{|l|}{ Education } \\
\hline High school/GED or some college & $151(51.0 \%)$ \\
\hline Two-year college degree (Associate's) & $59(19.9 \%)$ \\
\hline Four-year college degree (Bachelor's) or more & $86(29.1 \%)$ \\
\hline \multicolumn{2}{|l|}{ Relationship status } \\
\hline Not married or otherwise partnered & $88(29.7 \%)$ \\
\hline Married or otherwise partnered & $208(70.3 \%)$ \\
\hline \multicolumn{2}{|l|}{ Military service (ever active duty in U.S. Armed forces) } \\
\hline No & $224(75.7 \%)$ \\
\hline Yes & $72(24.3 \%)$ \\
\hline Time employed at current facility, years (Mean \pm SD) [Min, Max] & $7.78 \pm 6.58[0.08,29.3]$ \\
\hline \multicolumn{2}{|c|}{ Security level of Adults in Custody (AIC's), primarily worked with in the past month } \\
\hline Minimum & $75(25.3 \%)$ \\
\hline Medium & $130(43.9 \%)$ \\
\hline Maximum & $91(30.7 \%)$ \\
\hline \multicolumn{2}{|l|}{ Post, primarily worked in the past month } \\
\hline Non-housing unit & $120(40.5 \%)$ \\
\hline General population housing unit & $127(42.9 \%)$ \\
\hline Special housing/segregation unit & $49(16.6 \%)$ \\
\hline \multicolumn{2}{|l|}{ Shift, primarily worked in the past month } \\
\hline Day & $174(58.8 \%)$ \\
\hline Swing & $80(27.0 \%)$ \\
\hline Night & $42(14.2 \%)$ \\
\hline $\begin{array}{l}\text { Average hours worked per week, in the past month (Mean } \pm \text { SD) } \\
{[\text { Min, Max] }}\end{array}$ & $44.4 \pm 7.78[10,80]$ \\
\hline Perceived stress (PSS-4 Short Form) [15] (Mean \pm SD) [Min, Max] & $9.33 \pm 2.71[4,18]$ \\
\hline
\end{tabular}

a. Percentages add up to more than $100 \%$ since participants were asked to select all that applied.

aged (43.6 \pm 11.6 years) and the distribution of gender (36.5\% female) matches that of Oregon corrections as a whole, which employs about $30 \%$ females. A large percentage of the final sample is non-Hispanic white, which is consistent 
with the demographics of Oregon. For final analyses, race was dichotomized as Non-Hispanic white $(\mathrm{n}=235,79.4 \%)$ versus other $(\mathrm{n}=61,20.6 \%)$, including non-white, Hispanic, or more than one race. The highest level of education for most is a high school diploma, General Educational Development (GED), or some college compared to a two-year Associate's degree or more. Further, 70.3\% of participants are married or otherwise partnered and $24.3 \%$ served active duty in the military. The average time worked at participants current correctional facility was $7.78 \pm 6.58$ years, ranging from one month ( 0.08 years) to 29.3 years. The highest percentage of the sample primarily worked with medium security AIC's in the past month (43.9\%). In addition, the majority of primality worked in non-housing $(40.5 \%)$ or general population unit posts $(42.9 \%)$ and day shift $(58.8 \%)$ in the past month. Participants worked an average of $44.4 \pm 7.78$ hours per week, ranging from 10 to 80 hours. The average perceived stress score (PSS-4 Short Form) (15) was $9.33 \pm 2.71$, ranging from a minimum score of four to a maximum score of 18, and slightly skewed to the right (Figure 1).

Prior to use in the regression model, the consistency of the occupational constructs was determined using Cronbach's alpha $(\alpha)$ to ensure inter-reliability $(\alpha>0.70)$ using IBM SPSS Statistics 25. Each of these occupational constructs maintained inter-reliability among the sample (Cronbach's $\alpha>0.74$ ).

Unadjusted regressions with perceived stress as the outcome (Table 2) found insignificant associations with gender $(p=0.84)$, AIC's security level $(p=0.39)$, shift $(\mathrm{p}=0.36)$, years employed at current facility $(\mathrm{p}=0.31)$. Measures significantly associated with perceived stress (using $\alpha=0.25$ ) were work-related stress, work overload, environmental safety/dangerousness, possibility of AIC conflict, organizational stressors, operational stressors, resource insufficiency, procedural justice, organizational support, supervisor support, co-worker support, job satisfaction, intentions to quit, public image, age (all $\mathrm{p}<0.001$ ), experience violence $(\mathrm{p}=0.01)$, relationship status $(\mathrm{p}=0.02)$, work hours $(\mathrm{p}=0.02)$, witnessed

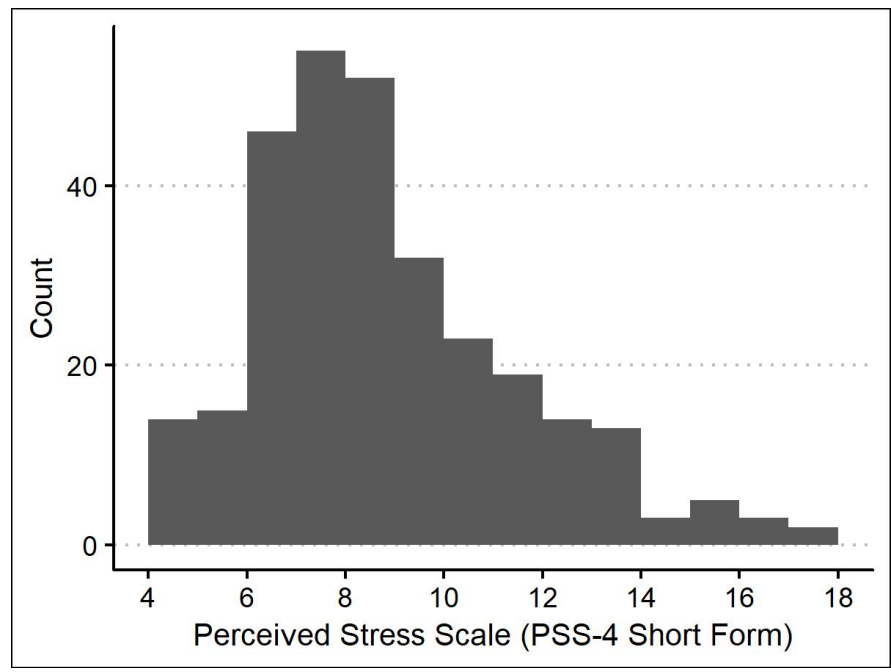

Figure 1. Distribution of perceived stress scale (PSS-4 short form) [15]. 
Table 2. Unadjusted associations between perceived stress in the past month and occupational related constructs, demographics, and work history.

\begin{tabular}{|c|c|c|}
\hline & $\begin{array}{l}\text { Estimate } \\
(95 \% \mathrm{CI})\end{array}$ & $P$-value \\
\hline \multicolumn{3}{|l|}{ Occupational related constructs } \\
\hline \multicolumn{3}{|l|}{ Job specific stress } \\
\hline Work-related stress & $1.34(1.02,1.66)$ & $<0.001$ \\
\hline Work overload & $0.75(0.41,1.08)$ & $<0.001$ \\
\hline \multicolumn{3}{|l|}{ Environmental } \\
\hline Environmental safety/dangerousness & $1.00(0.57,1.43)$ & $<0.001$ \\
\hline Possibility of conflict ${ }^{\mathrm{a}}$ & $0.83(0.48,1.18)$ & $<0.001$ \\
\hline \multicolumn{3}{|l|}{ Experienced violence, during the past six months } \\
\hline Less than once a month or more & 1.00 (ref) & \\
\hline Once a month or more & $0.97(0.29,1.65)$ & 0.01 \\
\hline \multicolumn{3}{|l|}{ Witnessed violence, during the past six months } \\
\hline Less than once a month or more & 1.00 (ref) & \\
\hline Once a month or more & $0.62(-0.02,1.25)$ & 0.06 \\
\hline \multicolumn{3}{|l|}{ Organizational } \\
\hline Organizational stressors $^{\mathrm{a}}$ & $0.92(0.62,1.22)$ & $<0.001$ \\
\hline Operational stressors & $1.27(0.98,1.57)$ & $<0.001$ \\
\hline Resource insufficiency & $0.83(0.55,1.10)$ & $<0.001$ \\
\hline Procedural justice & $1.28(0.83,1.73)$ & $<0.001$ \\
\hline Organizational support & $1.08(0.69,1.47)$ & $<0.001$ \\
\hline \multicolumn{3}{|l|}{ Work relationships } \\
\hline Supervisor support ${ }^{\mathrm{a}}$ & $0.84(0.50,1.17)$ & $<0.001$ \\
\hline Co-worker support & $0.98(0.55,1.40)$ & $<0.001$ \\
\hline \multicolumn{3}{|l|}{ Job contentment } \\
\hline Job satisfaction & $-1.31(-1.67,-0.96)$ & $<0.001$ \\
\hline Intentions to quit & $0.76(0.50,1.03)$ & $<0.001$ \\
\hline \multicolumn{3}{|l|}{ Outside of work } \\
\hline Public image & $0.93(0.53,1.33)$ & $<0.001$ \\
\hline \multicolumn{3}{|l|}{ Demographics } \\
\hline Age (years) & $-0.05(-0.07,-0.02)$ & $<0.001$ \\
\hline \multicolumn{3}{|l|}{ Gender } \\
\hline Female & 1.00 (ref) & \\
\hline Male & $0.07(-0.57,0.70)$ & 0.84 \\
\hline \multicolumn{3}{|l|}{ Race } \\
\hline Other (non-white or more than one race) & 1.00 (ref) & \\
\hline Non-Hispanic white & $-0.49(-1.25,0.26)$ & 0.20 \\
\hline \multicolumn{3}{|l|}{ Education $^{\mathrm{a}}$} \\
\hline High school/GED or some college & 1.00 (ref) & \\
\hline Two-year college degree (Associate's degree) & $0.46(-0.35,1.27)$ & 0.26 \\
\hline Four-year college degree (Bachelor's degree) & $-0.54(-1.25,0.17)$ & 0.14 \\
\hline
\end{tabular}




\section{Continued}

\begin{tabular}{|c|c|c|}
\hline \multicolumn{3}{|l|}{ Relationship status } \\
\hline Not married or otherwise partnered & 1.00 (ref) & \\
\hline Married or otherwise partnered & $-0.76(-1.43,-0.10)$ & 0.02 \\
\hline \multicolumn{3}{|l|}{ Military service (ever active duty in U.S. Armed forces) } \\
\hline No & 1.00 (ref) & \\
\hline Yes & $0.43(-0.28,1.14)$ & 0.24 \\
\hline \multicolumn{3}{|l|}{ Work history } \\
\hline Time at current facility (years) & $-0.02(-0.07,0.02)$ & 0.31 \\
\hline \multicolumn{3}{|c|}{$\begin{array}{l}\text { Adults in Custody (AIC's) security level, primarily worked } \\
\text { with in the past month }\end{array}$} \\
\hline Minimum & 1.00 (ref) & \\
\hline Medium & $0.54(-0.44,1.52)$ & 0.28 \\
\hline Maximum & $0.71(-0.33,1.76)$ & 0.18 \\
\hline \multicolumn{3}{|l|}{ Post, primarily worked in the past month } \\
\hline Non-housing unit & 1.00 (ref) & \\
\hline General population housing unit & $0.56(-0.13,1.25)$ & 0.11 \\
\hline Special housing/segregation unit & $0.70(-0.21,1.61)$ & 0.13 \\
\hline \multicolumn{3}{|l|}{ Shift, primarily worked in the past month } \\
\hline Day & 1.00 (ref) & \\
\hline Swing & $0.52(-0.22,1.27)$ & 0.16 \\
\hline Night & $0.34(-0.58,1.25)$ & 0.47 \\
\hline Average hours worked per week, in the past month & $0.05(0.01,0.09)$ & 0.02 \\
\hline
\end{tabular}

Note: Estimates are coefficients from linear mixed effects regression models with the Perceived Stress Scale (PSS-4 Short Form) [15] as the dependent variable and random effect for correctional facility $(\mathrm{n}=296)$, including the associated P-value. a. Excluded in the final model building for perceived stress due to strong relationship with other variables in the model.

violence $(p=0.06)$, education $(p=0.08)$, post $(p=0.18)$, race $(p=0.20)$, and military service $(\mathrm{p}=0.24)$.

All associations between demographic, work history, and occupational constructs were assessed before the model building process to eliminate multi-collinearity. Possibility of conflict, organizational stressors, supervisor support, and education were excluded in the rest of the model building progress due to their strong relationship with other variables in the model. More specifically, organizational stressors is significantly related to resource insufficiency $(r=$ $0.84)$, work-related stress $(r=0.66)$, and supervisor support $(r=0.65)$; possibility of conflict related with environmental safety/dangerousness $(r=0.57)$; supervisor support related with procedural justice $(\mathrm{r}=0.66)$ and co-worker support $(\mathrm{r}=$ $0.51)$ (all p's $<0.001)$; and education related to post $\left(\chi^{2}=13.12, \mathrm{p}=0.01\right)$.

After purposeful selection with the included variables significantly associated with perceived stress, the variables remaining in the perceived stress model were work-related stress, operational stressors, procedural justice, job satisfaction, relationship status, work hours, and time employed at current facility. Model 
Table 3. Occupational, demographic and work history associations with perceived stress in the past month among corrections professionals.

\begin{tabular}{|c|c|c|c|}
\hline & $\begin{array}{l}\text { Estimate } \\
(95 \% \mathrm{CI})\end{array}$ & $\begin{array}{l}\text { Standardized } \\
\text { estimate }^{\mathrm{a}} \\
(95 \% \mathrm{CI})\end{array}$ & P-value \\
\hline Work-related stress & $0.50(0.08,0.93)$ & $0.43(0.07,0.80)$ & 0.02 \\
\hline $\begin{array}{l}\text { Average hours worked per week, in the } \\
\text { past month }\end{array}$ & $0.04(0.00,0.08)$ & $0.31(0.04,0.59)$ & 0.03 \\
\hline Operational stressors & $0.60(0.23,0.98)$ & $0.57(0.22,0.92)$ & 0.002 \\
\hline Lack of procedural justice & $0.48(0.05,0.92)$ & $0.32(0.03,0.61)$ & 0.03 \\
\hline Job satisfaction & $-0.72(-1.1,-0.35)$ & $-0.58(-0.87,-0.28)$ & $<0.001$ \\
\hline \multicolumn{4}{|l|}{ Relationship status } \\
\hline Not married/otherwise partnered & 1.00 (ref) & 1.00 (ref) & \\
\hline Married/otherwise partnered & $-0.58(-1.15,-0.01)$ & $-0.58(-1.15,-0.01)$ & 0.05 \\
\hline Time employed at current facility, years & $-0.04(-0.08,0.00)$ & $-0.25(-0.52,0.01)$ & 0.06 \\
\hline
\end{tabular}

a. (Estimate - mean)/standard deviation. Note: Estimates are coefficients from a linear mixed effects regression model of the Perceived Stress Scale (PSS-4 Short Form) [15] with a random effect for correctional facility $(\mathrm{n}=296)$.

diagnostics indicated the final model was a good fit (Variance Inflation Factor > 5 , residual plots showed no major deviations from model assumptions, and overall model $\mathrm{p}<0.001$ ), and no additional transformations were necessary.

Results from the final model (Table 3 ) found that perceived stress increases with increased work-related stress $(p=0.02)$, work hours $(p=0.03)$, operational stressors $(p=0.002)$, and lack of procedural injustice $(p=0.03)$, and decreases with more time employed at current facility $(\mathrm{p}=0.06)$, improved job satisfaction $(\mathrm{p}<0.001)$, and among married or partnered individuals $(\mathrm{p}=0.05)$.

Standardized estimates of the final model were also created for each participant based on the difference of each score from the mean divided by the standard deviation. Based on these standardized estimates, operational stressors accounted for the greatest increase in perceived stress $(\beta=0.57)$, while job satisfaction accounted for the greatest decrease $(\beta=-0.58)$. Average hours worked per week $(\beta=0.31)$ and lack of procedural justice $(\beta=0.32)$ accounted for the smallest increase in perceived stress, while time employed at current facility ( $\beta=$ -0.25 ) was associated with the smallest decrease in perceived stress.

\section{Discussion}

This study found significant associations between perceived stress among corrections professionals and age, relationship status, and various occupational conditions, such as job specific stress (work-related stress, work overload), environmental (environmental safety and dangerousness, possibility of conflict, experienced violence), organizational (organizational and operational stressors, resource insufficiency, procedural justice, organizational support), work relationships (supervisor and co-worker support), job contentment (job satisfaction 
and intentions to quit), and outside of work (public image). When considering all possible demographic, work history, and occupational constructs included in this study using a purposeful selection approach, results indicate that corrections professionals' perceived stress increases with work-related stress, longer work hours, increased operational stressors, and lack of procedural justice. Factors reducing perceived stress included increased job satisfaction, longer tenure at a facility, and being partnered or married. Results also suggest that corrections work-related stress is most influenced by operational stressors and job satisfaction.

Certain of these factors align with prior findings among occupational groups. Work-related stress [16] [17] refers to negative overall feelings towards work such as tension, fatigue, pressure, frustration, anger and worry. It is known that increases in stress at work contributes to overall perceptions of stress. In fact, a 2019 American Psychological Association report found that 64\% of adults in the United States cited work as a significant source of stress [27]. Therefore, further exploring the occupational factors that remained in the stress model are also important to address in terms of mitigating stress among high stress occupations.

Operational stressors were constructs found to be significantly associated with perceived stress among corrections professionals. In this study, operational stressors [13] [22] [23] refer to occupational issues that contributed most to stress in the past month, such as shift work, mandatory overtime, and difficulty with work-life balance, such as managing social life outside of work, limited availability to spend with family and friends, and feeling like always on the job. This means when considering work-specific stressors, negative feelings towards these operational type factors are associated with increases in overall stress.

In addition, increases in work hours also contributed to stress, suggesting more hours spent at work also increases stress. The economic returns on the additional hours did not seem to mitigate the negative impact of long hours. These findings are consistent with previous research suggesting increases in occupational health issues [28] and work-family conflict [29] among those who work longer hours. This is especially apparent in an occupation such as corrections, which can require mandatory overtime to maintain operations.

Procedural justice [16] [17] [24] in this study refers to fairness of work-related procedures, such as inconsistencies with polices, rules and regulations in regard to disciplinary actions and promotions. A systematic review including the occupational constructs considered in this study, found that organizational structure and climate of correctional facilities have the most consistent relationship with work-related stress and burnout among staff [13]. These factors include unclear goals and policies, lack of procedural justice, lack of decision-making ability, and lack of organizational support. These findings are similar to the results of this study that procedural justice was most associated with increases in perceived stress. 
Results also found that increases in job satisfaction, which included enjoyment and pride in their job, were a protective factor for stress among corrections professionals. Other research also finds that job satisfaction is negatively associated with work-related stress, whereas positively associated with hope and self-efficacy [30]. In addition, current research suggests increasing social support at work in order to significantly reduce the impact of job demands and improve job satisfaction [20].

There are limitations of this study limiting the generalizability or results, including small sample size, low participation rate (34\% across facilities), and reduced geographical sampling distribution. Despite these limitations, our sample represented of the Oregon Department of Corrections' demographics. Further, controlling for the random effect of facility accounted for within facility differences to account for generalizing results to other correctional facilities in Oregon.

\section{Conclusion}

This study has identified possible predictors of stress among Oregon corrections professionals. These findings can inform the development of policy changes that improve working conditions among this high stress occupation. Further, interventions addressing these factors determined as the greatest predictors of stress can improve corrections professionals' mental well-being, physical health, job performance, and other economic outcomes.

\section{Acknowledgements}

We would like to thank Oregon Department of Corrections for their participation in this research.

\section{Conflicts of Interest}

The authors declare no conflicts of interest regarding the publication of this paper.

\section{Notice}

This project was supported by Award No. 2017-R2-CX-0036, awarded by the National Institute of Justice, Office of Justice Programs, U.S. Department of Justice. The opinions, findings, and conclusions or recommendations expressed in this publication/program/exhibition are those of the author(s) and do not necessarily reflect those of the Department of Justice.

\section{Outline}

- Corrections professionals experience some of the highest levels of chronic stress compared to other occupations, leading to poor mental and physical health as well as negative economic and occupational outcomes.

- This self-report survey is first to concurrently index various work factors on 
corrections professionals' stress levels.

- Results indicate work related factors such as work-specific stressors, work hours, operational stressors and lack of procedural justice significantly contribute to increase in overall stress levels. These differences can also be attributed to differences in job satisfaction, time currently employed at current correctional facility, and marital status.

- These findings can inform the development of work place health promotion interventions and policy changes to improve working conditions among this high stress occupation.

\section{References}

[1] Houtman, I., Jettinghoff, K. and Cedillo, L. (2007) Raising Awareness of Stress at Work in Developing Countries: A Modern Hazard in a Traditional Working Environment [Internet]. World Health Organization, Geneva.

https://www.who.int/occupational health/publications/raisingawarenessofstress.pdf

[2] Spinaris, C., Denhof, M. and Morton, G. (2013) Impact of Traumatic Exposure on Corrections Professionals [Internet]. National Institute of Corrections.

https://info.nicic.gov/virt/sites/info.nicic.gov.virt/files/06Impact of Traumatic Exp osure.pdf

[3] Kuehl, K.S. and Elliot, D.L. (2017) Stress and Well-Being of Correctional Officers. Medicine and Science in Sports and Exercise, 49, 1092.

https://doi.org/10.1249/01.mss.0000520008.25229.3e

[4] Konda, S., Reichard, A.A. and Tiesman, H.M. (2012) Occupational Injuries among U.S. Correctional Officers, 1999-2008. Journal of Safety Research, 43, 181-186.

https://doi.org/10.1016/j.jsr.2012.06.002

[5] Denhof, M.D. (2014) Occupational Stressors in Corrections Organizations [Internet]. U.S. Department of Justice National Institute of Corrections. https://s3.amazonaws.com/static.nicic.gov/Library/029743.pdf

[6] James, L. and Todak, N. (2018) Prison Employment and Post-Traumatic Stress Disorder: Risk and Protective Factors. American Journal of Industrial Medicine, 61, 725-732. https://doi.org/10.1002/ajim.22869

[7] James, L., Todak, N. and Best, S. (2017) The Negative Impact of Prison Work on Sleep Health. American Journal of Industrial Medicine, 60, 449-456. https://doi.org/10.1002/ajim.22714

[8] Morse, T., Dussetschleger, J., Warren, N. and Cherniack, M. (2011) Talking about Health: Correction Employees' Assessments of Obstacles to Healthy Living. Journal of Occupational and Environmental Medicine, 53, 1037-1045. https://doi.org/10.1097/JOM.0b013e3182260e2c

[9] Elliot, D.L., Kuehl, K.S., El-Ghaziri, M. and Cherniack, M. (2015) Stress and Corrections: Addressing the Safety and Well-Being of Correctional Officers. Corrections Today, 77, 40.

[10] United States Department of Labor (2013) Nonfatal Occupational Injuries and Illnesses Requiring Days away from Work, 2012 [Internet]. Bureau of Labor Statistics. https://www.bls.gov/news.release/archives/osh2 11262013.pdf

[11] Lambert, E.G., Minor, K.I., Wells, J.B. and Hogan, N.L. (2015) Leave Your Job at Work. The Prison Journal, 95, 114-134. https://doi.org/10.1177/0032885514563284

[12] Brower, J. (2013) Correctional Officer Wellness and Safety Literature Review [In- 
ternet]. United States Department of Justice Office of Justice Programs Diagnostic Center. https://s3.amazonaws.com/static.nicic.gov/Public/244831.pdf

[13] Finney, C., Stergiopoulos, E., Hensel, J., Bonato, S. and Dewa, C.S. (2013) Organizational Stressors Associated with Job Stress and Burnout in Correctional Officers: A Systematic Review. BMC Public Health, 13, Article No. 82. https://doi.org/10.1186/1471-2458-13-82

[14] Isenhardt, A. and Hostettler, U. (2020) Inmate Violence and Correctional Staff Burnout: The Role of Sense of Security, Gender, and Job Characteristics. Journal of Interpersonal Violence, 35, 173-207. https://doi.org/10.1177/0886260516681156

[15] Cohen, S., Kamarck, T. and Mermelstein, R. (1983) A Global Measure of Perceived Stress. Journal of Health and Social Behavior, 24, 385-396.

https://doi.org/10.2307/2136404

[16] Armstrong, G.S. and Griffin, M.L. (2004) Does the Job Matter? Comparing Correlates of Stress among Treatment and Correctional Staff in Prisons. Journal of Criminal Justice, 32, 577-592. https://doi.org/10.1016/j.jcrimjus.2004.08.007

[17] Castle, T.L. (2008) Satisfied in the Jail?: Exploring the Predictors of Job Satisfaction Among Jail Officers. Criminal Justice Review, 33, 48-63.

https://doi.org/10.1177/0734016808315586

[18] Moon, B. and Maxwell, S.R. (2004) The Sources and Consequences of Corrections Officers' Stress: A South Korean Example. Journal of Criminal Justice, 32, 359-370. https://doi.org/10.1016/j.jcrimjus.2004.04.006

[19] Cullen, F.T., Link, B.G., Wolfe, N.T. and Frank, J. (2006) The Social Dimensions of Correctional Officer Stress. Justice Quarterly, 2, 505-533. https://doi.org/10.1080/07418828500088711

[20] Brough, P. and Williams, J. (2007) Managing Occupational Stress in a High-Risk Industry. Criminal Justice and Behavior, 34, 555-567.

https://doi.org/10.1177/0093854806294147

[21] Fritz, C., Hammer, L., Guros, F. and Meier, D. (2015) Survey of Oregon Correctional Officers: Work Stress, Well-Being, and Work-Life Balance [Internet]. Oregon Department of Corrections. https://olis.leg.state.or.us/liz/2015R1/Downloads/CommitteeMeetingDocument/542 $\underline{15}$

[22] McCreary, D.R. and Thompson, M.M. (2006) Development of Two Reliable and Valid Measures of Stressors in Policing: The Operational and Organizational Police Stress Questionnaires. International Journal of Stress Management, 13, 494-518. https://doi.org/10.1037/1072-5245.13.4.494

[23] Summerlin, Z., Oehme, K., Stern, N. and Valentine, C. (2010) Disparate Levels of Stress in Police and Correctional Officers: Preliminary Evidence from a Pilot Study on Domestic Violence. Journal of Human Behavior in the Social Environment, 20, 762-777. https://doi.org/10.1080/10911351003749169

[24] Taxman, F.S. and Gordon, J.A. (2009) Do Fairness and Equity Matter? An Examination of Organizational Justice among Correctional Officers in Adult Prisons. Criminal Justice and Behavior, 36, 695-711. https://doi.org/10.1177/0093854809335039

[25] Wayne, S.J., Shore, L.M. and Liden, R.C. (1997) Perceived Organizational Support and Leader-Member Exchange: A Social Exchange Perspective. Academy of Management Journal, 40, 82-111. https://doi.org/10.5465/257021

[26] Bursac, Z., Gauss, C.H., Williams, D.K. and Hosmer, D.W. (2008) Purposeful Selection of Variables in Logistic Regression. Source Code for Biology and Medicine, 3, 
Article No. 17. https://doi.org/10.1186/1751-0473-3-17

[27] American Psychological Association (2019) Stress in America: Stress and Current Events. Stress in America TM Survey [Internet].

https://www.apa.org/news/press/releases/stress/2019/stress-america-2019.pdf

[28] Wong, K., Chan, A.H.S. and Ngan, S.C. (2019) The Effect of Long Working Hours and Overtime on Occupational Health: A Meta-Analysis of Evidence from 1998 to 2018. International Journal of Environmental Research and Public Health, 16, 2102. https://doi.org/10.3390/ijerph16122102

[29] Namazi, S., Dugan, A.G., Fortinsky, R.H., Barnes-Farrell, J., et al. (2019) Examining a Comprehensive Model of Work and Family Demands, Work-Family Conflict, and Depressive Symptoms in a Sample of Correctional Supervisor. Journal of Occupational and Environmental Medicine, 61, 818-828.

https://doi.org/10.1097/JOM.0000000000001664

[30] Law, F.M. and Guo, G.J. (2016) Correlation of Hope and Self-Efficacy with Job Satisfaction, Job Stress, and Organizational Commitment for Correctional Officers in the Taiwan Prison System. International Journal of Offender Therapy and Comparative Criminology, 60, 1257-1277. https://doi.org/10.1177/0306624X15574997 